\title{
Sources of Stress for Pharmacy Students in a Nationwide Sample
}

\section{ABSTRACT}

\section{Objective:}

The purpose of this study is to provide insight into the sources of stress experienced by current professional year pharmacy students in the United States.

\section{Methods:}

An online survey related to the sources of stress of current pharmacy students was distributed nationally. The survey included a section in which the respondent could choose any or all of 10 stress factors: coursework, grades, faculty, health concerns, family, current job market, finances, lack of sleep, friends, and "other." The Perceived Stress Scale (PSS) was also administered. Frequency and distribution of stressors and stress levels across professional year was also assessed.

\section{Results:}

A majority of respondents reported coursework, lack of sleep, finances, and grades as stressors. A minority of participants selected family, job market, faculty, friends, health concerns and "other" stressors. Grades, lack of sleep, and faculty had the largest association with increased PSS scores. P4 students reported significantly fewer stressors than other years. More advanced students were less likely to report lack of sleep, grades, or coursework, but were more likely to select the job market.

\section{Conclusion:}

Academic concerns are a primary source of stress for a large majority of the sample.

Development of interventions should focus on earlier professional years and emphasize the importance of sleep and physical health as students in these years report these stressors more frequently than advanced students. Further research is necessary to validate and extend the present findings.

Keywords: stress, stressors, doctor of pharmacy students, mental health 


\section{INTRODUCTION}

Stress, a psychological and physiological response to the demands of the environment, can be both negative (distress) and positive (eustress). ${ }^{1}$ Previous study results indicate that, while elevated stress is not necessarily harmful, extreme amounts of it can result in a variety of health and occupational consequences. ${ }^{2,3}$ It is important to assess excessive stress in educational settings to improve student learning and effectiveness and, ultimately, professional competence. In addition to the amount of stress individuals feel, it is important to understand the sources of stress in the environment (stressors). Stressors in the undergraduate population include financial burdens, new and increased academic demands, family/social issues, daily hassles, increased independence, and adjustment to a new environment and culture. ${ }^{4,5}$ Results from prior studies have found that students of healthcare professions (eg medical, dental, nursing and pharmacy students) report higher, more harmful levels of distress than do other students. ${ }^{1,6-8}$

Previous research results indicate a wide variety of stressors for students of health professions, including: examinations, grades, extensive amount of material to be learned, and unsupportive faculty. ${ }^{9-11}$ Additional stressors for medical students include social isolation, talking with patients, dealing with death and suffering, interacting with advisers, and working with cadavers. ${ }^{1,10}$ Other stressors are less specific to medical school, such as lack of leisure time or lack of feedback on progress. ${ }^{1,10}$ Dental students reported difficulty of class work, insufficient time to complete demanding assignments, financial burdens, atmosphere created by clinical

faculty, performance pressure, and patients arriving late or missing their appointments. ${ }^{9,10}$ Specific stressors for nursing students include administrative duties and conflict with doctors. ${ }^{1,11}$ Much less is known about the stressors of pharmacy students. 
Stress has become a major subject of concern in the design, delivery, and assessment of the pharmacy curriculum for educators, administrators, and governing bodies in the field of pharmacy education. Guideline 15.5 of the accreditation standards for pharmacy schools (established by the Accreditation Council for Pharmacy Education) states that schools and colleges of pharmacy must assess perceived stress in students, faculty, and staff. ${ }^{12}$ The reason for this criterion is to address ineffective learning experiences, prevent negative academic and programmatic outcomes, and increase student success and effectiveness. ${ }^{12}$ Better understanding the sources and amount of stress perceived by pharmacy students may address the ongoing concern that pharmacy students are over trained in their programs and feel underutilized in their profession. ${ }^{13-15}$

Similar to other programs, stress in the pharmacy student population corresponds to a host of negative personal (eg lower quality of life, more health problems), academic (eg lower grades), and professional outcomes (eg career dissatisfaction) ${ }^{1,14-20}$ Emerging evidence suggests that pharmacy students experience more psychological distress than other students of healthcare professions. ${ }^{6,8,21}$ However, there is a relative dearth of studies concerning the perceived stress, stressors, and coping strategies of pharmacy students. ${ }^{6}$ As a result, the amount of stress in pharmacy students is not yet established, nor is the exact origin of their stress; this impedes the ability to determine if the experiences of pharmacy students reflect the broader student population and/or students of healthcare professions. The scarcity of research on stress and mental health of pharmacy students makes it difficult to determine if interventions or curricular modifications are necessary for this population, and, if so, what those should entail. Addressing 
excessive stress and its origins can increase effectiveness of students as they transition into professional pharmacy practice.

While research suggests that pharmacy students have elevated, though not necessarily harmful levels of stress,$^{20}$ it is not yet established if their sources of stress mirror those of other students. Limited available data suggest that sources of stress in pharmacy students reflect those of other professional programs. Previously identified stressors for pharmacy students include: coursework and exams,,${ }^{1,17,19,22}$ financial concerns, ${ }^{1,17,19,22}$ lack of English proficiency, ${ }^{1}$ unsupportive faculty

or conflict with faculty, ${ }^{1,22}$ family, ${ }^{17,19}$ lack of social time, ${ }^{17}$ physical health issues,,${ }^{17,19}$ lack of sleep, ${ }^{17,23}$ and the job market. ${ }^{24}$

The purpose of the current analysis is to synthesize disparate findings related to sources of stress in pharmacy students. Identifying the number and type of stressors for pharmacy students, and how they relate to perceived stress, is a necessary step in determining if interventions or curricular changes are needed.

\section{METHODS}

Participants. The present analysis is a follow up from a previous paper in which the methods of data collection and descriptive statistics of the sample have been described in detail. ${ }^{20}$ Briefly, in late March through late April of 2010, 16000 current members of the American Pharmacists Association-Academy of Student Pharmacists (APhA-ASP) were invited to participate in an online survey pertaining to stress in pharmacy students in exchange for entry into a lottery for a $\$ 50$ cash prize. An additional reminder was sent out to the sample 2 weeks after the initial invitation. The invitations were distributed via email from the APhA-ASP database to an even 
number of current student members in each of the four program years (4000 invitations per program year) as well as broad distribution across regions of the United States, Puerto Rico, and Guam, to attain a diverse sample of pharmacy students nationwide. An identical e-mail was delivered to all invitees at both time points. Demographic composition of the sample can be seen in Table 1, modified from Votta and Benau. ${ }^{20}$ The sample was generally similar to the pharmacy student population at the time of data collection in terms of gender, ethnicity, program type, and professional year. ${ }^{20}$ Assessment of geographic region and university-specific information could not be attained as the APhA removed this information to ensure anonymity and confidentiality of their membership and security of their listserv.

Materials. We based the inventory of stressors on those reported in prior studies of pharmacy students and other students of healthcare professions. ${ }^{1,6,17,19,22}$ Students assessed 10 items by selecting the appropriate checkboxes in a checklist (there were no limits on the number of items that could be selected to proceed with the survey): coursework, grades, faculty, health concerns, family, current job market, finances, lack of sleep, friends, and, "other." The "other" item included a text field in which the participant could provide their open-ended response. The checklist methodology was chosen for its parsimony in assessing items that are most relevant to each participant. ${ }^{25,26}$ In addition to the 10-item stress source inventory, participants completed the 10-item Perceived Stress Scale (PSS). ${ }^{27}$ Each item on the PSS pertains to an individual's feelings of stress in the past month, for example: "In the last month, how often have you found that you could not cope with all the things that you had to do?" and "In the last month, how often have you felt you were on top of things?" Each item is scored on a Likert-type scale of 0 ("never") to 4 ("very often"). Scores on the PSS were the summation of all items (there are four reverse-scored items) ranging from 0 to 40 . The PSS has shown a high level of reliability and 
validity for use in nonclinical populations to assess individual differences of perceived stress; ${ }^{2,3,28}$ to our knowledge, there are no clinical cutoff scores for the scale. Higher scores indicate increased psychological stress and predict a variety of negative mental and physical health outcomes. ${ }^{2,3}$ Individual differences in PSS scores for this sample have been previously reported,$^{20}$ and the present sample showed good internal reliability on the instrument (Chronbach's $\alpha=.89$ ). Graduation year was collected via fill-in box.

Inclusion Criteria. Only complete surveys were included in the analyses to ensure retention of valid responses. Respondents were removed from all analyses if they failed to complete any demographic item or more than one question on the PSS. Surveys missing a single item (10\% of the scale) on the PSS had that single item replaced using imputation (the mean of the remaining 9 items, rounded to an integer) if all other items in the inventory were complete $(n=48)$. To our knowledge, validated methods for handling missing data on the PSS are unavailable, so we utilized a conservative data replacement procedure.

\section{Data Analysis.}

Total Stressors. We conducted a linear regression to assess how the total number of stressors an individual selected predicts the perceived stress via PSS scores. To determine if number of stressors varied by year, we ran a one-way ANOVA with post-hoc Tukey's $t$-tests comparing each year. Effect size for the one-way ANOVA was calculated as $\omega^{2}$, and is analogous to an $r^{2}$. Cohen's $d$ was calculated as the effect size for the pairwise comparisons of the total number of stressors between each program year.

Individual Stressors. To identify the largest sources of stress, we conducted multiple regression with each of the stressors in the model as predictor variables and PSS score as the dependent 
variable. Kendall's Tau-C $\left(\tau_{\mathrm{c}}\right)$ was used to assess the association of four professional years [P1 $(n=540) ; \mathrm{P} 2(n=518) ; \mathrm{P} 3(n=552) ; \mathrm{P} 4(n=573)]$ to each stressor. Kendall's $\tau_{\mathrm{c}}$ is a nonparametric correlation coefficient that is suited for analyzing associations between ordinal variables; it is calculated on the same scale as other coefficients (-1 to 1). Only results in which the absolute value of the $\tau_{\mathrm{c}}$ or $\beta$ coefficient are $\geq 0.10$ are considered meaningful. ${ }^{29}$

Statistical analyses were conducted using Stata 13 for Macintosh (StataCorp, College Station, TX). In order to determine the most frequently-reported "other" stressors, we conducted a word frequency analysis by using qualitative analytical software NVivo version 9.1 (QSR International, Doncaster, Victoria, Australia). The Institutional Review Boards of The University of the Sciences and the American Pharmacists Association approved the study design; all participants were provided with informed consent material prior to starting the survey.

\section{RESULTS}

A total of 2606 participants responded to the survey, which is a return rate of $16.3 \%$. After removal of incomplete surveys, the final sample consisted of 2232 participants, which is $85.6 \%$ of the returned surveys, or $14.0 \%$ of all invitees. Removal of individuals with imputed data did not affect significance or effect size in any of the analyses below.

The frequencies of each stressor selected are reported in Table 1. Only the first item (coursework), and the last item ("other") ranked in the same order as they appeared in the survey, which indicates limited response and/or order-effect bias: it is likely that most participants looked at the whole list of items and selected those most relevant to them, increasing the validity

of the data. ${ }^{25,26}$ Most individuals selected approximately 4 items $(M=4.30 \pm 1.74$, Median=4.0 Mode=4.0). 
Coursework was the most frequently reported stressor. The remaining stressors chosen by a majority of participants were, in this order: lack of sleep, finances, and grades. A minority of participants selected, in this order: family, job market, faculty, friends, health concerns and “other" stressors. The most frequently reported "other" stressors included: work/job (6.8\%), residency (4.9\%), extracurricular/activities (2.9\%), (lack of) time (2.1\%), organizations (1.9\%), board (exams) $(1.6 \%)$, wedding (1.5\%), relationships $(1.4 \%)$, rotations $(1.4 \%)$, and examinations $(1.2 \%)$. All remaining "other" stressors were reported by less than $1 \%$ of respondents to this question.

Relation of Stressors and PSS Scores. For the whole sample, the mean PSS score was 18.52 $( \pm 6.63)$. The results of linear regression show that the total number of selected stressors $(X)$ an individual selected was a moderate predictor of PSS scores (Y): the slope of the regression line was significantly greater than zero $\left[\right.$ Slope $=1.62 ; 95 \% \mathrm{CI}=1.48-1.77 ; \mathrm{t}_{(2231)}=22.3 ; p<.001 ; \mathrm{Y}$ $\left.=11.53+1.62 \mathrm{X} ; R^{2}=.182\right]$. More specifically, the number of stressors alone accounts for $18.2 \%$ of the variation in PSS scores, and each additional stressor a participant selected resulted in PSS scores increasing by approximately $1.62(4 \%)$. The results of multiple regression with each stressor as the independent variable and PSS scores as the dependent variable are presented in Table 2 . The results of this model showed that the only stressors with notable $\beta$ coefficients were grades (.235), lack of sleep (.182), faculty (.153), and family (.120). Health concerns, friends, "other," and the job market were statistically significant, but the $\beta$ for each were $<0.1$ and are considered marginal. Coursework and finances did not rise to a level of significance as predictors of stress in the model. 
Association of Program Year to Stressors. There was a significant main effect of the number of stressors selected in each program year $(p<.001)$, which had a small effect size $\left(\omega^{2}=.035\right)$. Results of post hoc Tukey's $t$-test show that the number of stressors reported by P1 $(\mathrm{M}=4.45, \pm$ 1.66), $\mathrm{P} 2(\mathrm{M}=4.59, \pm 1.70)$, and $\mathrm{P} 3(\mathrm{M}=4.40, \pm 1.72)$ did not significantly differ (p's > .2). Conversely, $\mathrm{P} 4$ students reported significantly fewer stressors $(\mathrm{M}=3.73, \pm 1.76)$ than the remaining 3 professional years ( $p$ 's <.001). There was a medium effect size when P4 was compared to $\mathrm{P} 3(d=.38), \mathrm{P} 2(d=.50)$, and $\mathrm{P} 1(d=.43)$. Table 5 presents the associations of professional year to each type of stressor. There was a fairly robust association of program year to each stressor. The results demonstrate that, as professional year increased, the likelihood of selecting grades, coursework, lack of sleep, friends, faculty, and health concerns significantly decreased. Conversely, as professional year increased, the likelihood of selecting the job market, “other," and family also increased. The notable $\tau_{\mathrm{c}}$ 's corresponded to grades and coursework (in which the likelihood of selecting this item decreased for each successive year), and the job market (which substantially increased with professional year).

\section{DISCUSSION}

The purpose of the present report is to provide insight into the sources of stress for pharmacy students in the United States. The total number of stressors selected by participants had moderate predictability on overall perceived stress; this indicates that there are other variables that can better account for perceived stress (eg demographics) and/or that there are qualitative aspects of the stressors that were not assessed and were outside the scope of the present study. The results indicate that primary sources of stress were coursework, grades, finances, and lack of sleep. Finally, program year predicted the selection of most stressors. 
Academic concerns are a primary source of stress for a large majority of the sample, consistent with other students of healthcare professions. ${ }^{9-11}$ The most frequently selected stress factor in the present study was coursework, similar to previous samples of pharmacy students. ${ }^{17,19,22} \mathrm{~A}$ majority of respondents also selected grades as a stressor. Interestingly, while grades had the strongest association with PSS scores, coursework was not a significant predictor in the same model. There are a few possible explanations for this finding. It may be that the amount of coursework is not a source of stress, but the evaluation of the work (ie grades) is. It may also be that, since a vast majority of respondents selected coursework, there was little variation associated with this item. Previous research suggests that the demanding course load of pharmacy students is perceived as eustress, but recent PharmD's are often disappointed with the actual demands of professional pharmacy practice compared to their coursework in school, especially those who work in community pharmacy. ${ }^{13-15}$ Increased disappointment corresponds to the likelihood of pursuing other careers. ${ }^{15}$ Additional research is needed to better understand if the demands of the pharmacy curriculum are excessive in comparison to what professional pharmacy entails, and what aspects of the curriculum can, or should, be modified to provide realistic preparation for pharmacy practice.

Lack of sleep was the second most selected stressor, and it also had the second strongest association with overall perceived stress. Based on our results, it is unclear what may be a contributing factor to insufficient sleep. Sleep disturbance in undergraduates and young adults can be both cause and consequence of poor time management, excessive coursework, psychological distress, and unawareness of the importance of sleep. ${ }^{30}$ Further, insufficient sleep has been linked to poor academic performance as well as negative physical and mental health outcomes. ${ }^{30,31}$ While preliminary evidence suggests that causes and consequences of sleep 
disturbance in pharmacy students mirror those of other student populations, ${ }^{23}$ further studies are needed to validate this finding and identify the underlying cause of pharmacy students not attaining sufficient sleep. It is notable that, in the present sample, there was a reduction in reported lack of sleep in later professional years; therefore, the importance of sleep hygiene should be emphasized to pharmacy students in early professional years.

Finances were reported as the third most common stressor. Previous samples of pharmacy students also reported finances as a primary stressor. ${ }^{1,17,19}$ Pharmacy students are not alone with this concern, as students in other health professions report finances as a primary source of stress. ${ }^{4,9,10}$ Adjusted for inflation, costs of higher education have almost doubled in the past 10 years. ${ }^{32}$ With limited free time to attain employment to supplement income and pay for education, it is not surprising that this would be reported as a major source of stress for pharmacy students.

Family, friends, and faculty were previously identified as primary stressors for pharmacy students. ${ }^{1,17,19}$ While a minority of respondents selected these items, faculty had the third, and family had the fourth, strongest association with increased stress levels. This indicates that faculty and family are a particularly meaningful stressor when applicable to the respondent. The studies that identified these as primary stressors in pharmacy students utilized free-write ${ }^{1,17}$ or a Likert-type rating scale ${ }^{19}$ to collect their data. Compared to checklists, open-ended and forcedchoice questions can generate remarkably different responses to the same question, ${ }^{25}$ where checklists are suggested to highlight responses that are most salient for respondents. ${ }^{26}$ Based on the current data, it is unclear why these items are associated with higher stress levels, and additional research is merited to better understand these findings. 
The job market was the only variable in the study where there was a notable increase in the likelihood of it being selected by students in later years of the program. There is evidence that the job market for recent pharmacy graduates is shrinking, ${ }^{33}$ and as a result, graduating doctors of pharmacy are more likely to pursue a residency position than in the past. ${ }^{24}$ This item may reflect concerns related to the changing landscape of the pharmacy job market. Schools and colleges of pharmacy may consider promoting a variety of career opportunities that a PharmD degree may provide, as well as emphasize training in transferrable skills for a broader range of careers than are presently promoted.

Health concerns were not a primary stressor, unlike what has been found previously for pharmacy students. ${ }^{19}$ Similar to medical students, ${ }^{34}$ pharmacy students may underreport or refuse treatment for health concerns because illness is stigmatized, or it is ignored in order to prevent academic consequences (eg missing rotations or exams). ${ }^{35}$ Another possibility is that this item may have been ambiguous, resulting in fewer participants selecting it. It should be noted that the item was close to having a notable $\beta$ coefficient in the model (.092) suggesting a notable association with PSS scores. Additionally, although the $\tau_{\mathrm{c}}$ was negligible, the likelihood of selecting this item significantly reduced across professional years. Health concerns in pharmacy students should be explored further.

"Other" factors were the least reported stressor. The most frequently stated item in response to this question was "work/job" and "residency." Limited interpretations to this item are possible due to the infrequency of repeated statements. 
Program year had a robust negative relationship to the selection of most stress factors in the inventory with the exception of the job-market, family, and "other" items, which increased with program year. Therefore, not only do $\mathrm{P} 3$ and $\mathrm{P} 4$ students demonstrate a decline in perceived distress, ${ }^{8,16,20}$ they also have fewer stressors. Pharmacy students in the P4 year have less coursework and graded material and, therefore, may be less likely to select these items. However, it is surprising that the likelihood of selecting lack of sleep and health concerns also decreased for P4 students. This indicates that students in later professional years not only report reduced stress, ${ }^{1,8,16,20}$ but this is associated with reduced physical health problems. It may be that students in later years experience less stress or have fewer demands on their time (eg fewer exams for which to study), leading to increased time for self-maintenance (eg sleep), subsequently reducing health problems. ${ }^{3,23,30}$ Alternatively, it may be that students learn how to structure their time in order to better take care of themselves as they progress through their program, or those who cannot cope with these stressors and stress levels do not remain in pharmacy training. Should this finding be replicated, it may be best to design interventions for earlier professional years that emphasize the importance of physical health as a means of alleviating stress.

\section{LIMITATIONS AND FUTURE DIRECTIONS}

Although this study examines stress in a national pharmacy student population, the results should be interpreted in consideration of some limitations. This study was cross-sectional, so these data can only be interpreted as descriptive. The goal of this study was to replicate previous inventories of stressors in pharmacy students to provide researchers additional avenues of research that may be insightful. Responses were reported via checklist, which is a novel method in collecting data pertaining sources of stress. Additionally, the reliability of using checklists to 
collect these data is not fully determined, and previous research suggests that this method can alter or bias response outcomes to the same question compared to other response types. ${ }^{25,26}$ Future research should use a variety of survey methods, as well as a larger and/or pharmacy student-specific list of stressors. Finally, while the size of the present sample is large, the response rate was somewhat low, and the survey was only available to student members of the APhA-ASP; this increases the likelihood of non-response bias and decreases the generalizability of the present findings to the broader pharmacy student population. It was beyond the scope and purpose of the present analyses to explore how non-responders may have differed from those who completed the study.

\section{CONCLUSION}

Coursework, lack of sleep, finances, and grades were reported as the most prevalent sources of stress, similar to results from previous samples. This may be the first study to report lack of sleep as a major source of stress for pharmacy students compared to many other stressors; additional work is needed to address this issue. Identifying stressors is an essential step in the ongoing effort to ameliorate pharmacy student stress. The results of the present report can inform future research and the development of interventions in colleges and schools of pharmacy to improve the mental health and success of pharmacy students. 


\section{References:}

1. Dutta AP, Pyles MA, Miederhoff P. Measuring and understanding stress in pharmacy students. In: Landow MV, ed. Stress and mental health of college students. New York: Nova Science Publishers; 2006:1-28.

2. Cohen S, Janicki-Deverts D. Who's stressed? Distributions of psychological stress in the united states in probability samples from 1983, 2006, and 2009. J Appl Soc Psychol. 2012;42(6):1320-1334. doi: 10.1111/j.1559-1816.2012.00900.x

3. Cohen S, Janicki-Deverts D, Miller GE. Psychological stress and disease. JAMA. 2007;298(14):1685-1687. doi: 10.1001/jama.298.14.1685

4. Brougham RR, Zail CM, Mendoza CM, Miller JR. Stress, sex differences, and coping strategies among college students. Curr Psychol. 2009;28(2):85-97. doi: 10.1007/s12144009-9047-0

5. Beck DL, Hackett MB, Srivastava R, McKim E, Rockwell B. Perceived level and sources of stress in university professional schools. J Nurs Educ. 1997;36(4):180. PMCID: 9107596

6. Dutta A, Pyles M, Miederhoff P. Stress in health professions students: Myth or reality? A review of the existing literature. J Natl Black Nurses Assoc. 2005;16(1):63-68. PMCID: 16255316

7. Murphy RJ, Gray SA, Sterling G, Reeves K, DuCette J. A comparative study of professional student stress. J Dent Educ. 2009;73(3):328-337.

8. Henning K, Ey S, Shaw D. Perfectionism, the imposter phenomenon and psychological adjustment in medical, dental, nursing and pharmacy students. Med Educ. 1998;32:456464. PMCID: 10211285

9. Alzahem A, van der Molen H, Alaujan A, Schmidt H, Zamakhshary M. Stress amongst dental students: A systematic review. Eur J Dent Educ. 2011;15(1):8-18. PMCID: 21226800

10. Schmitter M, Liedl M, Beck J, Rammelsberg P. Chronic stress in medical and dental education. Med Teach. 2008;30(1):97-99. doi: 10.1080/01421590701769571

11. Tully A. Stress, sources of stress and ways of coping among psychiatric nursing students. J Psychiatr Ment Health Nurs. 2004;11(1):43-47. PMCID: 14723638

12. Accreditation Council for Pharmacy Education. Accreditation standards and guidelines for the professional program in pharmacy leading to the doctor of pharmacy degree. Chicago, IL: ACPE; 2011.

13. While A, Shah R, Nathan A. Interdisciplinary working between community pharmacists and community nurses: The views of community pharmacists. J Interprof Care. 2005;19(2):164-170. doi: 10.1080/13561820400024142

14. Ortmeier BG, Wolfgang AP, Martin BC. Career commitment, career plans, and perceived stress: A survey of pharmacy students. Am J Pharm Educ. 1991;55:138-142.

15. Wolfgang AP, Ortmeier BG. Career commitment, career plans, and job-related stress: A follow-up study of pharmacy students as pharmacists. Am J Pharm Educ. 1993;57(1):2528. 
16. Hirsch JD, Do AH, Hollenbach KA, Manoguerra AS, Adler DS. Students' health-related quality of life across the preclinical pharmacy curriculum. Am J Pharm Educ. 2009;73(8):1-6. PMCID: 20221340

17. Marshall LL, Allison AA, Nykamp D, Lanke, S. Perceived stress and quality of life among doctor of pharmacy students. Am J Pharm Educ. 2008;72(6):1-8. PMCID: 2661164

18. Richardson M, Abraham C, Bond R. Psychological correlates of university students' academic performance: A systematic review and meta-analysis. Psychol Bull. 2012;138(2):353-387. doi: 10.1037/a0026838

19. Frick LJ, Pharm BS, Dey S. Student stress in a three-year doctor of pharmacy program using a mastery learning educational model. Am J Pharm Educ. 2011;75(4):1-6. PMCID: 3138348

20. Votta RJ, Benau EM. Predictors of stress in pharmacy students: Results from a nationwide survey. Curr Pharm Teach Learn. 2013;5(5):365-372. doi: 10.1016/j.cptl.2013.06.014

21. Mimura C, Murrells T, Griffiths P. The association between stress, self-esteem and childhood acceptance in nursing and pharmacy students: A comparative cross-cultural analysis. Stress and Health. 2009;25(3):209-220. doi: 10.1002/smi.1240

22. Canales-Gonzales PL, Kranz, P.L. Percecived stress by students in a pharmacy curriculum. Education. 2008;129(1):139-146.

23. Taher YA, Samud AM, Ratimy AH, Seabe AM. Sleep complaints and daytime sleepiness among pharmaceutical students in tripoli. Libyan J Med. 2013;7(1). PMCID: 23118811

24. Khan A, Griffin B, Schumacher C. Pharmacy students' perceptions of postgraduate pharmacy residency programs and job outlook in an economic recession-phase i. Curr Pharm Teach Learn. 2012;4(2):137-145. doi: 10.1016/j.cptl.2012.01.006

25. Schuman H, Presser S. Questions and answers in attitude surveys: Experiments on question form, wording, and context: SAGE; 1996.

26. Smyth JD, Dillman DA, Christian LM, Stern MJ. Comparing check-all and forced-choice question formats in web surveys. Public Opin Q. 2006;70(1):66-77. doi: 10.1093/poq/nfj007

27. Cohen S. Perceived stress scale-10 item. N.D.; http://www.psy.cmu.edu/ scohen/PSS.html. Accessed February 25, 2014.

28. Roberti JW, Harrington LN, Storch EA. Further psychometric support for the 10-item version of the perceived stress scale. J Coll Couns. 2006;9(2):135-147. doi: 10.1002/j.2161-1882.2006.tb00100.x

29. Cohen J. Power primer. Psychol Bull. 1992;112:155-159. PMCID: 19565683

30. Millman RP. Excessive sleepiness in adolescents and young adults: Causes, consequences, and treatment strategies. Pediatrics. 2005;115(6):1774-1786. PMCID: 15930245

31. Lund HG, Reider BD, Whiting AB, Prichard JR. Sleep patterns and predictors of disturbed sleep in a large population of college students. J Adolesc Health. 2010;46(2):124-132. PMCID: 20113918

32. United States Department of Education. Tuition costs of colleges and universities. Digest of Education Statistics 2012; http://nces.ed.gov/fastfacts/display.asp?id=76. Accessed February 25, 2014. 
33. Brown DL. A looming joblessness crisis for new pharmacy graduates and the implications it holds for the academy. Am J Pharm Educ. 2013;77(5). PMCID: 3687123

34. Moutier C, Cornette M, Lehrmann J, et al. When residents need health care: Stigma of the patient role. Acad Psychiat. 2009;33(6):431-441. doi: 10.1176/appi.ap.33.6.431

35. Roberts LW, Warner TD, Trumpower D. Medical students' evolving perspectives on their personal health care: Clinical and educational implications of a longitudinal study. Compr Psychiat. 2000;41(4):303-314. PMCID: 10929800 
Table 1

Demographic characteristics of the sample

\begin{tabular}{ll}
\hline Characteristics & $\mathrm{N}(\%)^{\mathrm{a}}$ \\
\hline Male & $619(28)$ \\
Female & $1613(72)$
\end{tabular}

Ethnicity

American Indian or Alaska Native $6(0)$

Asian

391 (18)

Black or African American

$83(4)$

Native Hawaiian or other Pacific

Islander

$14(1)$

White

$1573(71)$

Hispanic or Latino

$83(4)$

Other

$82(4)$

Year

2010

$540(24)$

2011

$518(23)$

2012

$552(25)$

2013

$622(28)$

Program Type

Direct Entry (0-6)

317 (14)

Two/Four System (P1 to P4)

$1614(72)$

Post Graduate

$301(14)$

GPA

1.99 or below

$2(0)$

$2.00-2.49$

45 (2)

$2.50-2.99$

$251(11)$

$3.00-3.49$

864 (39)

$3.50-4.00$

1030 (46)

Prefer not to answer

$40(2)$

${ }^{a}$ Percentages are rounded to an integer 
Table 2.

Frequency of stressors selected by whole sample

\begin{tabular}{llcc}
\hline Rank & Stressor & Survey Order & Percent $^{\mathrm{a}}$ \\
\hline \hline 1. & Coursework & 1 & 85 \\
2. & Lack of Sleep & 9 & 65 \\
3. & Finances & 4 & 61 \\
4. & Grades & 6 & 58 \\
5. & Family & 3 & 37 \\
6. & Job Market & 8 & 33 \\
7. & Faculty & 2 & 25 \\
8. & Friends & 5 & 25 \\
9. & Health Concerns & 7 & 25 \\
10. & Other & 10 & 16 \\
\hline${ }^{a}$ percentages are rounded to integers &
\end{tabular}


Table 3:

Results of multiple regression with all stressors as the independent variable and PSS scores as the dependent variable

\begin{tabular}{|c|c|c|c|c|c|}
\hline & $B$ & $\begin{array}{l}\text { Standard } \\
\text { Error of B }\end{array}$ & $95 \%$ CI of $B$ & $\begin{array}{l}\text { Contribution } \\
\quad \text { to } R^{2}(\beta)\end{array}$ & $p$ \\
\hline Intercept & 12.206 & .397 & 11.43 to 12.99 & -- & $<.001$ \\
\hline Coursework & 0.663 & .380 & -0.08 to 1.41 & .036 & .081 \\
\hline Faculty & 2.332 & .290 & 1.76 to 2.90 & .153 & $<.001$ \\
\hline Family & 1.651 & .263 & 1.14 to 2.17 & .120 & $<.001$ \\
\hline Finances & -0.066 & .263 & -0.58 to 0.45 & -.005 & .80 \\
\hline Friends & 1.316 & .292 & 0.74 to 1.89 & .086 & $<.001$ \\
\hline Grades & 3.155 & .278 & 2.61 to 3.70 & .235 & $<.001$ \\
\hline Health Concerns & 1.418 & .296 & 0.84 to 2.00 & .092 & $<.001$ \\
\hline Job Market & 0.813 & .271 & 0.28 to 1.35 & .058 & .003 \\
\hline Lack Sleep & 2.518 & .275 & 1.98 to 3.06 & .182 & $<.001$ \\
\hline Other & 1.089 & .343 & 0.42 to 1.76 & .060 & .002 \\
\hline$R^{2}$ & & & .222 & & \\
\hline$F$ & & & 63.38 & & $<.001$ \\
\hline
\end{tabular}


Table 4

Percent $^{\mathrm{a}}$ of each professional year that reported each stressor

\begin{tabular}{|c|c|c|c|c|c|c|}
\hline & $\left(n=\frac{\mathrm{P} 1}{=5} 40\right)$ & $\left(n=\frac{\mathrm{P} 2}{=5} 18\right)$ & $(n \stackrel{\mathrm{P} 3}{=552)}$ & $\left(n=\frac{\mathrm{P} 4}{=573)}\right.$ & $\tau_{\mathrm{c}}$ & Sig. \\
\hline Coursework & 92 & 94 & 93 & 59 & -.248 & 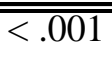 \\
\hline Faculty & 25 & 34 & 25 & 19 & -.062 & .002 \\
\hline Family & 35 & 37 & 36 & 42 & .046 & .047 \\
\hline Finances & 61 & 57 & 58 & 68 & .051 & .026 \\
\hline Friends & 29 & 28 & 27 & 16 & -.097 & $<.001$ \\
\hline Grades & 73 & 74 & 62 & 20 & -.420 & $<.001$ \\
\hline Health Concerns & 28 & 28 & 22 & 21 & -.062 & .002 \\
\hline Job Market & 23 & 22 & 35 & 56 & .276 & $<.001$ \\
\hline Lack of Sleep & 69 & 73 & 62 & 54 & -.136 & $<.001$ \\
\hline Other & 11 & 14 & 21 & 19 & .075 & $<.001$ \\
\hline $\begin{array}{l}\text { PSS Scores } \\
{[\text { Mean (SD)] }}\end{array}$ & $\begin{array}{l}19.47 \\
(6.42)\end{array}$ & $\begin{array}{l}19.89 \\
(6.26)\end{array}$ & $\begin{array}{l}18.22 \\
(6.36)\end{array}$ & $\begin{array}{l}16.30 \\
(6.90)\end{array}$ & -- & -- \\
\hline
\end{tabular}

a percentages are rounded to an integer 